Original Article

\title{
A STUDY ON MORPHOLOGY OF THE BICEPS BRACHII MUSCLE
}

\author{
Ramakrishna Avadhani', K. Kalyan Chakravarthi' \\ ${ }^{1}$ Professor, Department of Anatomy, Yenepoya M edical College, Yenepoya University,
} Deralakatte, Mangalore - 575018.

${ }^{2}$ Lecturer, Department of Anatomy, Dr. Pinnamaneni Siddhartha Institute of M edical Sciences \& Research Foundation, Chinnaoutpalli, Gannavaram Mandal, Krishna District (AP), INDIA-521286.

\section{Correspondence:}

\section{K. Kalyan Chakravarthi',}

Lecturer, Department of Anatomy, Dr. Pinnamaneni Siddhartha Institute of M edical Sciences \& Research Foundation, Chinnaoutplli, Gannavaram Mandal, Krishna District (AP), INDIA - 521286.

Mobile : 81422 14159. E-mail: kalyankosuric@gmail.com

\begin{abstract}
:
The anatomical variations and abnormalities of the muscles of the upper limb have become significant because of new imaging techniques, such as computed tomography and magnetic resonance imaging. Among the three muscles of the anterior compartment of the arm, a very uncommon anomaly of the biceps is having three or more heads. Knowledge of the existence of the three headed or four headed biceps brachii may become significant in preoperative diagnosis and during surgery of the upper limb. The present study was undertaken to observe the anomalous origin, insertion and the incidence of three or more heads of biceps brachii in the adult human cadavers. This study was carried out on 24 human cadavers at Dr. Pinnamaneni Siddhartha institute of medical sciences \& research foundation (Dr. PSIM S\& R.F) Gannavaram; Krishna Dist; A.P. Variant biceps brachii may cause compression of neurovascular structures because of their close relationship to brachial artery and median nerve. The surgeons and traumatologists have to keep such muscular variations in mind.
\end{abstract}

Keywords : Biceps brachii, brachioradialis, coracobrachialis, third and fourth head of biceps brachii.

\section{Introduction :}

Biceps brachii muscles only flexor muscle of the arm which crosses the shoulder as well as the elbow joint. It is one of the most variable muscles in the human body, in terms of number and morphology. ${ }^{1}$ It is characteristically described as a two-headed muscle that originates proximally by a long head and a short head. The long head originates from the supraglenoid tubercle of the scapula, and the short head originates from the coracoid process of the scapula. ${ }^{1}$ Distally, these two heads join to form a common tendon which inserts into the radial tuberosity, and some aponeurotic fibres form the bicipital aponeurosis which merges with the deep fascia of the forearm. This muscle

Access this article online Quick Response Code

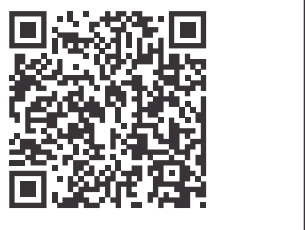
mainly contributes to flexion and supination of the forearm. ${ }^{1}$ Testut has described the biceps brachii muscle as one of the muscles with most frequent anatomical variations. ${ }^{2}$ Variant biceps brachii may confuse a surgeon who performs procedures on the arm and may lead to iatrogenic injuries.

\section{Materials And Methods:}

This study was carried out on both upper extremities of 24 human cadavers irrespective of age and sex during the period of 2010 - 2012 academic years for the undergraduate teaching purpose at Pinnamanen Siddhartha institute of medical sciences \& research foundation Gannavaram; Krishna Dist; A.P (INDIA). Details of the additional heads and morphology of biceps brachii in the 48 arms of 24 cadavers were studied and appropriate photographswere taken.

\section{Results:}

Among 48 arms studied: Eight had biceps brachii with three heads on the left side (16.67\%); one had rare four headed biceps brachii on the right side (2.08\%); one had unusual non united two heads of biceps brachii (2.08\%); one had the bicipital aponeurosis merging with the brachioradialis $(2.08 \%)$; one had unique anomalous origin of 
coracobrachialis (2.08\%) (Graph-1). In the unusual ununited two heads of biceps brachii short head continued as a bicipital aponeurosis and long head as a bicepital tendon (Fig-1). In the three headed biceps brachii third head was of humeral origin, which inserted into the radial tuberosity by a common tendon with the long and short heads (Fig-2). In the four headed biceps brachii the accessory third head was mainly arising from the anterolateral surface of shaft of humerus and joined the long head at the level where the latter joined the short head. The fourth head arising from the short head and inserting in to the antero-medial surface of shaft of humerus above the insertion of coracobrachialis (Fig-3). In the unique anomalous origin of coracobrachialis three fourth of Coracobrachialis arising from the short head of biceps brachii and one fourth arising from Pectoralis minor (Fig-5).

The results of the present study was compared with that of previous studies from medical literature shows that the occurrence of such anomalies of the biceps brachii muscle was relatively very rare.

\section{Discussion:}

The biceps brachii is one of the most variable muscles in the human body, in terms of its heads and morphology ${ }^{3}$. In this study, we found an unusual ununited two heads of biceps brachii on the right side in which short head continued as a bicipital aponeurosis and long head as a bicepital tendon (Fig-1); we also found that, the bicipital aponeurosis radiating in to the radial side and merging with the brachioradialis in proximal part of forearm (Fig-4). Such anomaly of biceps brachii was not documented previously.

The most common variation is the muscle arising from proximal humerus. This variation is also known as the humeral head or third head of the biceps brachii muscle. Gray's Anatomy reported the incidence of this variation to be as much as $10 \%,{ }^{4}$ which concurs with the observations of Bergman et al in white Europeans. ${ }^{5}$ The supernumerary heads of biceps brachii muscle are classified according to their locations as superior, infero-medial and infero-lateral heads. ${ }^{6}$ Testut reported acromial, labial and pectoral heads of supernumerary heads of biceps brachii. ${ }^{7}$ Kosugi et al observed that the supernumerary head of biceps arose from the humerus between the insertion of coracobrachialis and upper part of origin of brachialis and from medial intermuscular septum. ${ }^{8} \mathrm{He}$ also reported that in a few cases, the biceps brachii was seen to be arising from the tendon of the pectoralis major, the deltoid, the articular capsule, or the crest of the greater tubercle. ${ }^{8} \mathrm{Abu}$ Hijleh reported that the supernumerary bicipital head originated from the anteromedial surface of the humerus just below the insertion of coracobrachialis. ${ }^{9}$

Asvat et al observed that the third head of biceps brachii originated from the humeral shaft either inferior to, and in common with, the insertion area for the coracobrachialis, or in common with the brachialis muscle. ${ }^{10}$ They also observed a dual origin in which the medial fibres originated from the short head of biceps and the lateral fibres from the deltoid fascia. ${ }^{10}$ Sweiter and Carmichael emphasized that the incidence of the third head of the biceps is more on the right side. ${ }^{11}$ However, contrary to it, in the present study, eight cases of the third head were found in the left upper limbs. Incidence of third head of biceps brachii observed in the present study (16.66\%) are higher than the incidence reported by Asvat et al ( South African white), Nakatani et al, Kopuz et al Rai et al, Ravindranath et al and Santo Neto et al, Poudel and Bhattarai and Soubhagya R et al (Table-1). But Incidence of third head of biceps brachii is lesser than the incidence reported by Asvat et al (South African black) and Khaledpour (Table-1).

Musculocutaneous nerve passing between supernumerary heads, or supernumerary heads pierced by musculocutaneous nerve has been reported. ${ }^{12}$ This intramuscular course of musculocutaneous nerve is usually reported to be associated with its interconnection with median nerve. ${ }^{12}$ In this study, such communication was observed (FIG-2). Intramuscular course is a potential compression site and compression of nerve in between heads of biceps may lead to paraesthesia and weakness of elbow flexion and supination due to involvement of brachialis and nerve to long head of biceps. Hsu et al. reported a small case series of injuries of this nerve with 
Graph-1: Showing the results of morphology of the Biceps brachii muscle

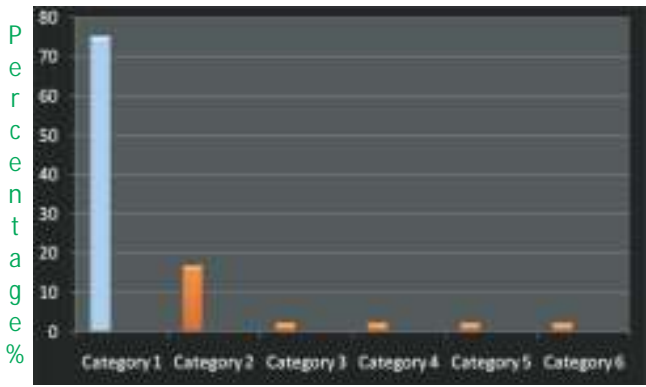

Category1- Normal two headed biceps brachii (79.16\%); Category2- Incidence of three headed biceps brachii (16.66\%); Category3- Incidence of four headed biceps brachii (2.08\%); Category4- Incidence of ununited two heads of biceps brachii $(2.08 \%)$; Category5- Incidence of anomalous bicipital aponeurosis attachments (2.08\%); Category6- Incidence of other muscles originating from the biceps brachii (2.08\%); Category5- Incidence of anomalous bicipital aponeurosis attachments (2.08\%); Category6- Incidence of other muscles originating from the biceps brachii $(2.08 \%)$;

Figure-1: Anterior compartment of right arm showing non-union of two heads of biceps brachii

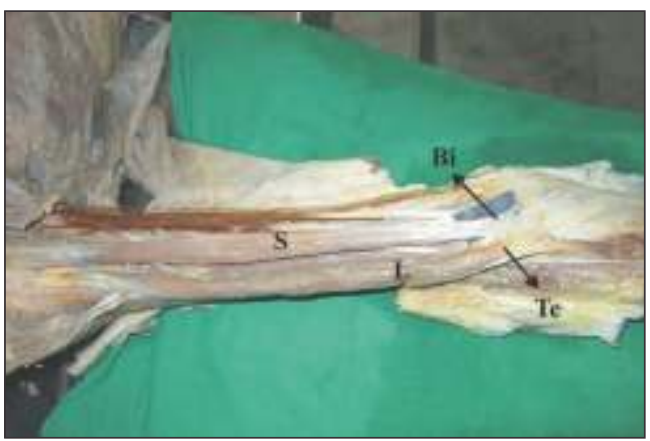

S - Short head of biceps brachii continuing as a bicipital aponeurosis. L - Long head of biceps brachii continuing as a tendon. Bi - Bicipital aponeurosis. Te - Biceps Tendon.

Figure-2: Anterior compartment of left arm showing $3^{\text {rd }}$ head of biceps brachii and musculocutaneous nerve interconnection with median nerve

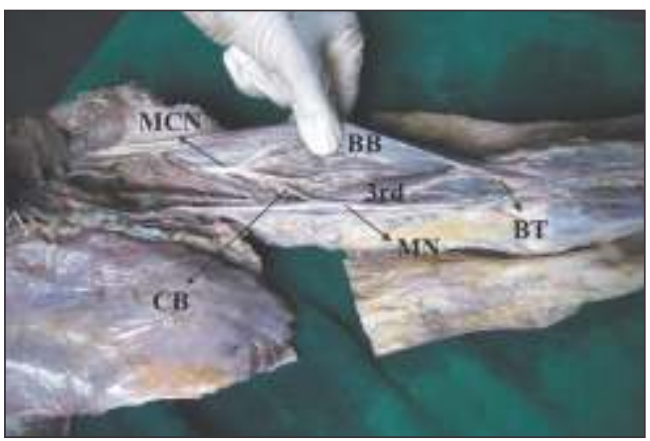

$3^{\mathrm{RD}}$ - Third head of biceps brachii; BT- Biceps Tendon; BB-Biceps Brachii; MCN-M usculocutaneous Nerve; CN- Communicating Branch; M N- M edian Nerve
Figure-3: Anterior compartment of right arm showing 4 headed biceps brachii

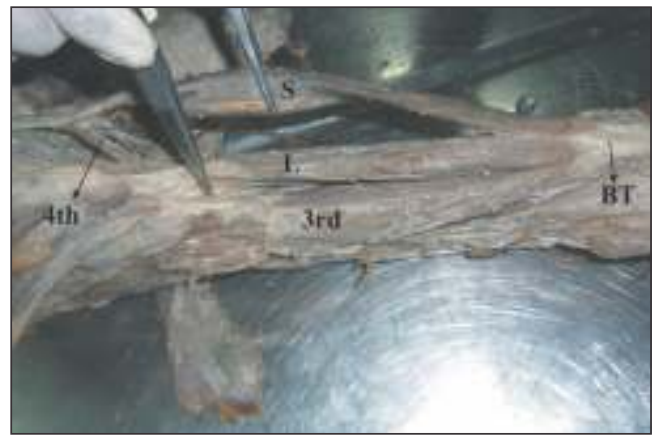

S - Short head of biceps brachii; L - Long head of biceps brachii; $3^{\mathrm{RD}}$ - Third head of biceps brachii forming common tendon with the long and short heads: $\mathbf{4}^{\mathrm{TH}}$ - Third head of biceps brachii originating from the short head of biceps brachii. BT - Biceps Tendon.

Figure-4: Anterior compartment right arm and forearm showing bicipital aponeurosis which merging with the brachioradialis muscle

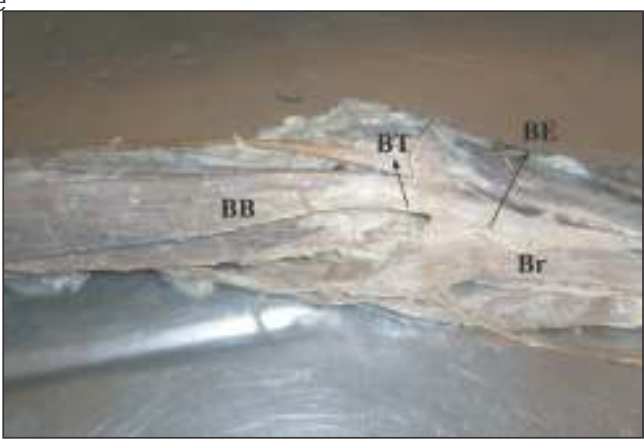

BB -Biceps Brachii; BT - Biceps Tendon; BE - Bicipital Aponeurosis; Br-Brachioradialis

Figure-5 : Anterior compartment of right arm showing origin of coraco brachialis from pectoralis minor and biceps brachii

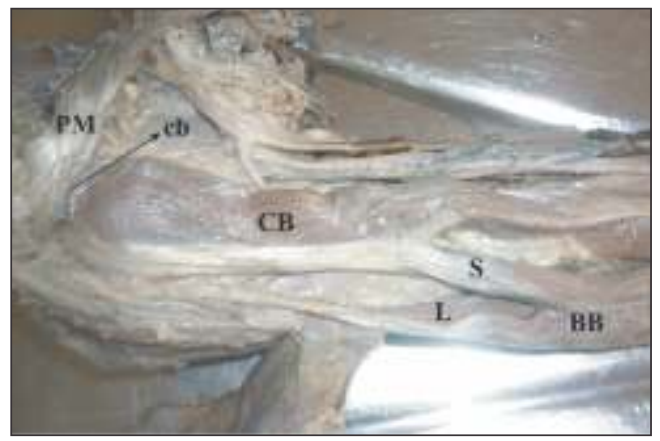

S - Short head of biceps brachii; L-Long head of biceps brachii; BB -Biceps Brachii; PM - Pectoralis minor; CB - Three fourth of Coracobrachialis arising from the short head of Biceps brachii; cb-One fourth of coracobrachialis arising from pectoralis minor.

varied mechanism ranging from strenuous exercise to weight lifting, throwing of football etc. ${ }^{13}$ Biceps brachii will be useful as a component of flap surgery Mas et al (2006); 
Table-1: Showing incidence of third head of biceps brachii

\begin{tabular}{|c|c|}
\hline Research Workers & $\begin{array}{l}\text { Incidence of third head } \\
\text { of biceps brachii } \\
\text { (Percentage) }\end{array}$ \\
\hline Asvat et al. (1993) ${ }^{9}$ & $\begin{array}{c}20.5 \% \\
\text { (South African black) }\end{array}$ \\
\hline Asvat et al. (1993) ${ }^{9}$ & $\begin{array}{c}8.3 \% \\
\text { (South African white). }\end{array}$ \\
\hline Nakatani et al. (1998) $)^{16}$ & $8 \%$ \\
\hline Kopuz et al. (1999) ${ }^{17}$ & $15 \%$ \\
\hline Rai et al. (2007) ${ }^{18}$ & $\begin{array}{c}7.1 \% \\
\text { (Indian population) }\end{array}$ \\
\hline Ravindranath et al. (2005) ${ }^{19}$ & $1.8 \%$ \\
\hline Poudel and Bhattarai (2009) ${ }^{20}$ & $\begin{array}{c}12.5 \% \\
\text { (Nepalese population) }\end{array}$ \\
\hline Santo Neto et al $(1998)^{21}$ & $\begin{array}{c}9 \% \\
\text { (Blacks) }\end{array}$ \\
\hline Khaledpour (1985) ${ }^{22}$ & $31.2 \%$ \\
\hline Soubhagya R et al. $(2006)^{23}$ & $2 \%$ \\
\hline Present study & $16.66 \%$ \\
\hline
\end{tabular}

in such cases the knowledge of the innervation of accessory head as well as the compression of vasculature will be very much required by surgeons. ${ }^{14}$

Four headed biceps brachii muscles are reported in the literature by various authors. ${ }^{15,16}$

However in the current study, the accessory third head of four headed biceps brachii was mainly arising from the antero-lateral surface of shaft of humerus and joined the long head biceps brachii at the level where the latter joined the short head. The fourth head arising from the short head and inserting in to the antero-medial surface of shaft of humerus above the insertion of coracobrachialis. (Fig-3)

Such variations in muscle arise primarily due to-

$\mathrm{G}$ genetic composition,

$\mathrm{G}$ an inheritance carried over from ancient origins,

$\mathrm{G}$ many or most variations are totally benign,

$\mathrm{G}$ some are errors of embryologic developmental timing or persistence of an embryologic condition.

\section{Conclusion:}

Knowledge of the existence of the three or four heads of the biceps brachii may become significant in preoperative diagnosis and during surgery of the upper limbs. We believed the supernumerary heads observed in the present study might be significant in producing the strong flexion as well as supination of forearm. They may cause compression of neurovascular structures because of theirs close relationship to the brachial artery and median nerve. Therefore, surgeons, in particular orthopedic surgeons, should be aware of these anatomical variations of biceps brachii when dealing with some of the clinical syndromes.

\section{References:}

1. Williams PL, Bannister LH, Berry M M , et al, eds. Gray's Anatomy: The Anatomical Basis Of M edicine And Surgery, 38th ed. Edinburgh: ELBS Churchill Livingstone, 1995: 843.

2. Testut L. En:Tratado de Anatomia Humana. Barcelona: Salvat, 1902; 1022.

3. Sargon M F, Tuncali D, Celik HH. An unusual origin for the accessory head of biceps brachii muscle. Clin Anat. 1996; 9: 160-162.

4. Williams PL, Warwick R, Dyson M, Bannister LH. Myology. In: Gray's Anatomy, 37th ed. Churchill Livingstone, Great Britain, 1989; 632.

5. Bergman RA, Thompson SA, Afifi AK, Saadeh FA. Compendium of human anatomic variation. Baltimore, Urban \&Schwarzenberg. 1988; 139-143.

6. Rodriguez-Niedenfuhr N, Vazque T, Choi D, Parkin I, Sanudo JR: Supernumerary humeral heads of biceps brachii muscle revisited. Clinical Anatomy, 2003; 16(3):197-203.

7. Testut L: Signification anatomique du chef humeral du muscle biceps. Bulletins M emories de la sciete d' anthroplogic de paris. 1883; 6:238-245.

8. Kosugi K, Shibata S, Yamashita H. Supernumerary head of biceps brachii and branching pattern of musculocutaneous nerve in Japanese. Surg Radiol Anat 1992; 14:175-85.

9. Abu-Hijleh MF. Three-headed biceps brachii muscle associated with duplicated musculocutaneous nerve. Clin Anat 2005; 18:376-9.

10. Asvat R, Candler P, Sarmiento EE. High incidence of the third head of biceps brachii in South African populations. J Anat 1993; 182:101-4.

11. Swieter MG, Carmichael SW: Bilateral three headed biceps brachii muscle. Anatomisher Anzeiger, 1980;148(4):346-349.

12. Vazquez T, Rodriguez-Niedenfuhr M , Parkin I, Sanudo JR. A rare case of a four-headed biceps brachii muscle with a double piercing by the musculocutaneous nerve. Surg Radiol Anat. 2003; 25: 462-464.

13. Hsu JC, Paletta GA Jr, Gambardella RA, Jobe FW. M usculocutaneous nerve injury in major league baseball pitchers: a report of 2 cases. Am J Sports Med. 2007; 35: 1003-1006.

14. Mas N, Pelin C, Zagyapan R, Barhar H: Unusual Relation of the Median Nerve with the Accessory Head of the Biceps Brachii Muscle: An original case Report. Internatonal Journal of M orphology, 2006; 24(4): 561- 564

15. Nayak SR, Ashwin K, Madhan KS, Latha VP, Vasudha S, M erin M T. Fourheaded biceps and triceps brachii muscles, with neurovascular variation. Anatomical Sci Int'I 2007; 83: 107-11.

16. Nakatani T, Tanaka S, Mizukami S. Bilateral four-headed biceps brachii muscles: the median nerve and brachial artery passing through a tunnel formed by a muscle slip from the accessory head. Clin Anat. 1998; 11 (3): 209-12.

17. Kopuz C, Sancak B, Ozbenli S. On the incidence of third head of biceps brachii in Turkish neonates and adults. Kaibogaku Zasshi 1999; 74:301-5.

18. Rai R, Ranade AV, Prabhu LV, Pai M M , Prakash. The third head of the biceps brachii in the Indian population. Singapore M ed. J. 2007; 48(10): 929.

19. Ravindranath G, Jayasree N, Rajasree TK, Rao NR. The three headed biceps brachii - a case report. J. Anat. Soc. India. 2005; 54(1): 70.

20. Poudel PP, Bhattarai C. A study on the supernumerary heads of the biceps brachii muscle in the Nepalese population. Nepal Med. Coll. J. 2009; 11(2): 96-9.

21. Santo Neto H, Camalli JA, Andrade JC, M eciano Filho J, Marques MJ. On the incidence of the biceps brachii third head in Brazilian white and blacks. Ann Anat 1998; 180: 69-71.

22. Khaledpour C. [Anomalies of the biceps muscle of the arm]. Anat Anz 1985; 158:79 85. German.

23. Soubhagya R, Nayak, Latha $V$, et al. Third head of biceps brachii: a rare occurrence in the Indian popula-tion. Ann Anat 2006; 188:159-61. 